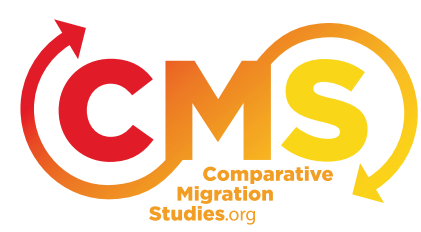

\title{
Comparative Migration Studies: an introduction
}

\author{
Sawitri Saharso \& Peter Scholten
}

CMS 1 (1): 1-6

DOI: $10.5117 / C M S 2013.1 . S A H A$

\section{A new journal with a comparative orientation}

This inaugural issue marks the launch of the new journal Comparative Migration Studies (CMS). Over the past decades, and especially since the 1970 s and 1980s, migration studies has evolved rapidly as a research field rooted in various disciplines. Like the phenomenon of migration itself, migration research has become increasingly globalized, which is manifested by the many migration research institutes across the world where academics from various disciplines work together.

CMS will promote comparative migration research based on the firm belief that comparative work will promote the theoretical development of migration research as only through comparison can we discover what is specific to a case. We understand comparative research in a broad sense and is involving four main areas (a point developed by Marco Martiniello in his contribution to this issue). One type compares people, which can be groups or categories of migrants in a particular situation. Another compares places, which could, for instance, be nations but also supranational entities, regions, cities, municipalities or neighbourhoods. A third type involves comparisons between different (historic) periods, adding a historical dimension to comparative research. Finally, as migration research is a multi-disciplinary field drawing from various disciplines and competing theoretical perspectives, the fourth type involves comparisons between these different disciplines and theoretical perspectives. CMS will promote engagement by scholars in all these areas of comparative research across disciplines and different theoretical perspectives.

CMS has no preferred geographical focus and intends to adopt a global approach to its search for the best comparative research on international 
migration. Migration research was and regularly still is rather nationally oriented and focussed on South-North migration. This can mean a relative neglect of South-South migration movements. CMS journal was founded to stimulate researchers to go beyond a strictly national orientation in the belief that cross-national comparison is and will continue to be important as international migration is necessarily about movement across national borders. International migration thus impacts on the development, consolidation and transformation of the nation state system, as well as challenges to it. Migration researchers therefore continue to compare across states, yet increasingly also focus on the supranational or international levels, as well as exploring the sub-national, including regions and big cities.

CMS adopts a broad definition of migration in the sense that we actively encourage contributions that explore not only the process of migrating, but also to the factors that trigger migration and to the consequences of this migration for both countries and destination countries. This could involve, for example, studies of migration processes and policies as well as economic, social, legal and political determinants of migration and processes related to ethnicity and migrant incorporation that are subsequent to migration. As such, CMS invites contributions on diverse facets of migration, including immigration/emigration, social and economic remittances, integration, assimilation, migration policies, migration law, incorporation policies, governance of migration and integration, ethnic/cultural/religious diversity, migrant rights, gender and migration, migration and citizenship, migration and national identity, migration and security, civic integration, nationalism and migration and ethnic entrepreneurship.

\section{An open access journal}

CMS is an open access journal. It is driven by the belief that open access publishing is the best strategy for promoting the exchange of knowledge and information in the social sciences in the $21^{\text {st }}$ century. Open access guarantees the widest possible readership for the work published in the journal, without commercial interference. For CMS authors, being able to reach out to a wide audience of peers through published work that is accessible is increasingly important and promote both recognition and citation.

The academic peer review procedures of CMS follow the double-blind peer review procedure that is standard for academic journals in our field. The editorial committee, assisted by a broad, international and multidisciplinary advisory committee will ensure that the work submitted to 
CMS is closely reviewed. This policy will also apply to submission of special issues in which each, single article will be subject to review.

Open access also enables CMS to publish faster than many other journals in our field. Once an article is approved following review, it will be published immediately. At the same time, we will also keep publishing journal issues, including special issues as well as open issues; per year we will publish at least 4 issues. In the future, as open access becomes normalized in the social sciences, we will publish only special issues as issues while individual articles will be published on a rolling basis.

Open Access gives CMS academic freedom. The absence of a commercial publishing interest enables CMS to publish top quality work when we want it and how we want it. This requires that we also pursue the author-pays model. Yet, with the help of academics that invest their time into CMS, the support of Amsterdam University Press and with funding from a start-up grant generously provided by the Dutch Science Foundation, we will only ask for a relatively small author-pays fee which will only be required for special issues and paid only for accepted articles. For now we are able to process and publish individual article submissions free of charge.

\section{This inaugural issue}

This inaugural issue of CMS provides a 'flash-forward' perspective on the meaning of comparative research for the development of migration studies. It does not aim or intend to be another state-of-the-art of migration studies. Rather, it identifies a number of research topics that we believe to be increasingly important research niches for the coming decades. It also involves articles that are comparative in various ways as identified before and bring insights from different disciplines. Furthermore, we have consciously sought to being together articles that develop different comparative research designs and use different (qualitative as well as quantitative) research methods.

The issue opens with a contribution by Marco Martiniello on Comparisons in Migration Studies. Here Martiniello elaborates four types of comparative research in migration studies and identifies several promising directions for future comparative migration research. Amongst others, Martiniello makes the argument for more gender comparative research (see for instance King a.o. in this issue), city-to-city comparisons (see for instance Phalet a.o. in this issue) and interregional and intercontinental comparisons (such as North-South comparisons but also transatlantic comparisons such 
as that developed by Street in this issue). These are directions to which CMS will attribute high priority in the years to come.

The article by Alex Street on the dynamics of naturalization decisions in the context of migrant families offers an excellent example of the sort of comparative research this journal seeks to promote. By comparing findings from Austria and the United States, Street builds a theoretical argument about naturalization behavior at the family level. One of the reasons this article was selected for the inaugural issue lies in its focus on the family level as a relatively under-explored level of analysis.

Another issue that is likely to become increasingly important concerns how debate about migrant incorporation and citizenship relates to the more general political and academic debate about on civil rights. In a USCanadian comparison, Irene Bloemraad and Doris Marie Provine show how civil rights are conceived and sometimes extended to foreign-born residents in different nations. In their article, they also lay the foundation for a comparison between Europe and Oceania.

Gender matters in the study of migration, also because migration may impact on gender relations in migrants' households. The article by Russell King, Diana Mata-Codesal and Julie Vullnetari addresses gender in relation to another key research concern for which comparative research is inevitable; migration and development. Combining data from Ecuador and Albania, the authors focus in particular on the effect of remittances on gender relations in these two countries. As such, they offer an intriguing perspective on how migration can affect social relations not just in the country of destination but also the country of origin of migrants.

Mathias Czaika's article asks whether unequal countries are more migratory. In an impressive comparative design, bringing together data from around 200 countries, Czaika focuses in particular on religious, ethnic and linguistic fractionalization of societies and its correlation with the propensity to migrate to show that ethnic and linguistic fractionalization increases the propensity to emigrate, whereas, surprisingly, this is less the case for religious fractionalization. This article shows the relevance of a global perspective on the root causes of migration and the value of comparative research in this respect.

Two articles then focus on what has become and is likely to remain an important topic in migration studies for some time to come, the role of Islam in society. Pursuing an ambitious comparative research design, Phalet, Maliepaard, Fleischmann and Güngör compare religious identification amongst Turkish and Moroccan Muslims in a number of cities throughout Europe (in Belgium, Germany, the Netherlands and Sweden) to show that 
religious boundaries are reinforced in West European cities by social inequality and by the accommodation of religious institutions. This article develops not solely an important research topic, but also provides a good example of the type of city-to-city comparisons is increasingly important in migration studies.

The second article by Christopher Cochrane focuses on a highly controversial and salient topic, which is attitudes of Muslims to same-sex marriage through comparison of Muslims to other religions in Canada, as well as comparing different types of Muslim in Canada. It confirms that religiosity increases the likelihood of negative opinions on same-sex marriages and also shows that there is a greater heterogeneity amongst Canadian Muslims in this respect, correlating with the extent of religiosity, level of education and residence period in Canada. This article also shows how single-case studies contribute to comparative research.

The final article of this inaugural issue adopts a more policy-scientific perspective on one of the central research topics in this field: asylum migration. From a comparative perspective, the 'communitarisation' of asylum policies at EU level has had an important converging effect on asylum policies in European countries. Using the concept of vertical venue-shopping, Kaunert, Léonard and Hoffmann show that refugee-assisting NGOs have increasingly organized and mobilized at EU level and exerted influence on policymaking.

Our intention is that this inaugural issue of CMS will help to set comparative research agendas for migration studies. There are, of course, many important research topics that are not addressed in this inaugural issue, but we hope that in years to come people will look back at this inaugural issue and be able to assess the importance of these contributions to the development of new research niches. CMS will provide a forum for excellent comparative research in the field of migration studies, with a keen eye for new and evolving research niches.

\section{About the authors}

Sawitri Saharso, VU University Amsterdam.

E-mail: s.saharso@vu.nl.

Peter Scholten, Erasmus University Rotterdam.

E-mail: p.scholten@fsw.eur.nl. 


\section{(c) (i) (8) $\Theta$}

NC ND 2013 Saharso \& Scholten / Amsterdam University Press.

This is an Open Access article distributed under the terms of the Creative Commons Attribution License (http:// creativecommons.org/licenses/by/2.o), which permits unrestricted use, distribution, and reproduction in any medium, provided the original work is properly cited. 